\title{
Pollen contamination and nonrandom mating in a Eucalyptus camaldulensis Dehnh seedling seed orchard
}

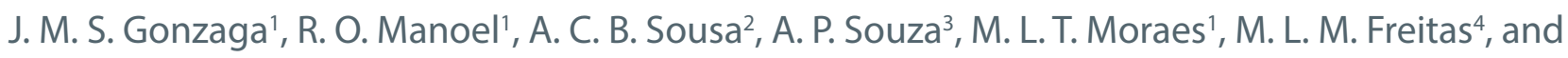 \\ A. M. Sebbenn ${ }^{4 *}$
}

1 Faculdade de Engenharia de Ilha Solteira/UNESP, CP 31, CEP 15385-000, Ilha Solteira, SP, Brazil

2 Centro de Biotecnologia, Universidade Federal da Paraíba, João Pessoa, CEP 58051-900, Paraíba, Brazil

3 Centro de Biologia Molecular e Engenharia Genética, Universidade Estadual de Campinas, Campinas CEP 13083-970, São Paulo, Brazil

4 Instituto Florestal de São Paulo, CP 1322, CEP 01059-970, São Paulo, SP, Brazil

* Corresponding author: A. M. Sebbenn, Phone: +0055 19 34351681, E-mail: alexandresebbenn@yahoo.com.br

\begin{abstract}
Eucalyptus camaldulensis has potential for timber, energy, pulp and cellulose production in Brazil due to its ability to adapt to a variety of environmental conditions. The use of improved seeds, selected for economic growth traits, is necessary to increase productivity of commercial stands. Seed seedlings orchards (SSO) are one option for improved seed production. However, pollen contamination from unimproved populations, as well as non-random mating in the SSO, can decrease the predicted genetic gains in selected populations. Thus, we investigate the mating system, pollen flow and dispersal patterns in an E. camaldulensis SSO and progeny test (PT), established with seedlings collected in the SSO, using seven microsatellite loci. All trees in the SSO were mapped, sampled, and genotyped. For the PT, we sampled, genotyped, and measured the total height of seedlings from 25 families. We detected $10 \%$ inbreeding in the PT, resulting mainly from selfing. Furthermore, we found a correlated mating rate of $18.5 \%$ in the SSO, indicating that within the PT there are some full-sibs. Using paternity analysis, we found $14.7 \%$ pollen contamination and a pattern of pollen dispersal between near neighbor trees in the SSO. We found $9.5 \%$ of inbreeding depression for seedlings height. Due to pollen contamination and nonrandom mating in the SSO, the actual genetic gains for growth traits in the PT are probably lower than the predicted genetic gains. We discuss some management strategies in the SSO that can be used to increase genetic gains in commercial reforestation established using seeds collected from the SSO
\end{abstract}

Keywords: Eucalyptus, gene flow, mating system, microsatellite loci, tropical trees

\section{Introduction}

Eucalyptus camaldulensis Dehnh is a new species being studied in Brazil for use in commercial reforestation in typically water deficient regions. This species has the largest natural geographic distribution in Australia ( $15.5^{\circ}$ to $38^{\circ} \mathrm{S}$, at altitudes ranging from 30 to $600 \mathrm{~m}$ ) and it is found in all states, except Tasmania (Butcher et al., 2002). It occurs in a range of environments, from tropical rain forest to dry forest with an annual precipitation ranging 250 to $625 \mathrm{~mm}$, dry season lasting from four to eight months, and temperatures from 20 to $28^{\circ} \mathrm{C}$ (Nieto and Rodriguez, 2003; Pryor, 1976). The species is a straight, fastgrowing tree that can reach 25 to $30 \mathrm{~m}$ in height and $1.0 \mathrm{~m}$ in diameter at breast height (dbh). The root system is quite powerful due to the presence of lignotubers, which provide resistance to cold and drought. The species is able to withstand a minimum temperature of $-6.7^{\circ} \mathrm{C}$ and maximum of $52.8^{\circ} \mathrm{C}$. E. camaldulensis also grows in several types of soils. The high levels of genetic diversity within and among natural populations of E. camaldulensis Butcher and Williams (2002) indicate the significant potential of the species for tree breeding. Due to its adaptation to different ecological conditions, with respect to rainfall, soil and other factors, the species has wide genetic variability and plasticity in terms of the ability to adapt to different environmental conditions in Brazil. This adaptability allows for quick identification of the most convenient provenance for rapid growth, and together with the vigorous stump sprouting, provides short-term benefits (Nieto and Rodriguez, 2003). In general, the wood of E. camaldulensis is hard, heavy, and used in building construction, wooden rollers, paper, pulp, plywood boards and chipboard, carpentry, firewood and charcoal. It is also planted for shade, windbreaks, 
and is important in beekeeping as the flowers enable the production of excellent quality honey (Nieto and Rodriguez, 2003).

Our team is genetically improving $E$. camaldulensis populations for production in the Brazilian savanna, using a seedling seed orchard (SSO) and progeny testing. The transformation of provenance and progeny test in seedling seed orchards is not a new concept. This was proposed by Nanson (1972) to decrease the time to obtain improved seeds in tree breeding programs. Seed orchards are important for forest improvement and the success of short- and long-term commercial stands depends on the genetic quality of the seeds produced by the orchards (Kaya et al., 2006). The main objectives in establishing seed orchards are to maximize breeding processes and preserve genetic diversity of produced seeds for commercial reforestation (Chaix et al., 2010). Genetic quality of seeds is affected by the selfing rate, mating among related individuals, correlated mating, pollen contamination from outside sources, and individual variation in female and male fecundity (Chaix et al., 2010). All these process can reduce the genetic quality of seeds and limit the predicted genetic gains of the orchards. Thus, studies of pollen flow, mating system, and pollen dispersal distance are extremely important to maintain the genetic quality of seeds produced in seed orchards (Wang, 2004). Understanding the selfing rate, paternity correlation, and individual variation in outcrossing allows us also to adjust the additive genetic variance, and give more precise estimates of heritability, parent and offspring breeding values, and genetic gains of quantitative and qualitative traits (Askew and Elkassaby, 1994; Chaix et al., 2010; El-Kassaby et al., 2015; Miranda et al., 2013).

Genetic markers, such as allozyme and microsatellite loci, and paternity analysis have been used extensively to evaluate mating patterns and pollen contamination in seed orchards (Burczyk et al., 2004). However, in order to guarantee a sufficient exclusion power ( $>0.97$ ) to exclude non-pollen parents of sampled seeds, paternity analysis requires loci markers with a high level of polymorphism in terms of number of alleles per locus (Ashley, 2010). Such studies have been carried out in order to estimate the selfing rate (Moriguchi et al., 2004; Stoehr and Newton, 2002), orchard contamination with foreign pollen from outside sources (Burczyk et al., 2002; Chaix et al., 2010; Grattapaglia et al., 2014; Grattapaglia et al., 2004; Kaya et al., 2006; Moriguchi et al., 2004; Slavov et al., 2005; Stoehr and Newton, 2002), variation in female and male reproductive success or female ovule and pollen contribution (El-Kassaby et al., 2010; Plomion et al., 2001; Stoehr and Newton, 2002), distance of pollen dispersal inside the orchard (Burczyk et al., 2002), identification of pollen source trees (Moriguchi et al., 2004; Slavov et al., 2005), selection of plus trees in the seed orchard (Grattapaglia et al., 2014; Grattapaglia et al., 2004), and pedigree reconstruction (El-Kassaby et al., 2015; El-Kassaby et al., 2010; Funda et al., 2014). In order to avoid contamination with external, unimproved pollen, seed orchards are generally established in locations that are spatially isolated from stands of the same species, and they are designed to favor the reproduction of a large number of different genotypes. Nevertheless, several studies have demonstrated pollen contamination, selfing, mating among relatives, and an imbalance in gametic contribution in SSOs (Burczyk et al., 2002; Chaix et al., 2010;
El-Kassaby et al., 2010; Grattapaglia et al., 2004; Kaya et al., 2006; Plomion et al., 2001). As noted above, such mating processes can decrease the expected genetic gains in commercial stands established from open-pollinated seeds collected from seed orchards.

Eucalyptus species have a mixed mating system, with relatively high outcrossing rates that are maintained by protandry and varying levels of self-incompatibility (Potts et al., 1987). A study conducted on four $E$. camaldulensis populations found high outcrossing rate (ranging from 0.912 to 0.995 ), low rate of mating among relatives (ranging from 0.021 to 0.034 ), and low paternity correlation, ranging from 0.079 to 0.365 (Butcher and Williams, 2002), demonstrating inbreeding and different levels of relatedness within families such as self-sibs, full-sibs, halfsibs, and self-half-sibs. Inbreeding produces inbreeding depression in Eucalyptus species, decreasing rates of survival, reproduction, and growth, as has been reported for E. regnans (Griffin and Cotterill, 1988), E. globulus (Hardner and Potts, 1995; Silva et al., 2011), E. nitens (Hardner and Tibbits, 1998), E. urophylla (Wu et al., 2015), and E. grandis (Chaix et al., 2010; Hedrick et al., 2016). Consequently, we expect reduced evidence of inbreeding between seed and adult stages.

The aims of this study were to investigate the genetic diversity, inbreeding, inbreeding depression, mating system, and pollen flow and dispersal patterns in a seedling seed orchard (SSO) and progeny test (PT) of E. camaldulensis, using microsatellite loci. The study was based on a census of all trees in a SSO and a seedling sample of the PT, established from the SSO. Specifically, we addressed the following questions: i) Are the levels of genetic diversity similar among SSO and PT? ii) Is the SSO spatially genetically structured and what is the variance effective population size? iii) Are there individuals originating from selfing, mating among relatives, and correlated mating in the SSO and PT? iv) Is the SSO reproductively isolated from pollen flow from other stands of the species and other Eucalyptus species? v) What is the pollen dispersal distance and pattern in the SSO? iv) What is the inbreeding depression for selfed seedlings, seedlings originating from mating among relatives, and all inbred seedlings (from selfing and mating among relatives)?

\section{Material and Methods}

\section{Seedling seed orchard}

The E. camaldulensis seedling seed orchard (SSO) used in this study was established using within family selection from a provenance and progeny test (PP) which was established from open-pollinated seeds collected at two locations in Australia. The seeds of PP were collected directly from seed trees in Australia (AP), including 13 seed trees (1 to 13) from Nott's Crossing, Katherine River (lot 14517), and 12 seed trees (14 to 25) from the CSIRO breeding program (lot 13923). The PP was established in April, 1986, at the Ilha Solteira Research and Teaching Farm $\left(20^{\circ} 20^{\prime} \mathrm{S}, 51^{\circ} 23^{\prime} \mathrm{E}\right.$, altitude of $\left.370 \mathrm{~m}\right)$, Ilha Solteira Campus (FEIS/UNESP), located in the Municipality of Selvíria, Mato Grosso do Sul State, Brazil. The site at FEIS/UNESP is characterized as moderately flat with a climate classified as 
Aw, average annual temperature of $24.5^{\circ} \mathrm{C}$, annual average humidity of $64.8 \%$, and average annual rainfall of 1,232 $\mathrm{mm}$. The local soil has been classified as oxisoil clay, moderate, hipidistrophic, kaolinitic, ferric compressed, very deep, and moderately acid (EMBRAPA, 1999). The PP was established using a randomized block design with 25 progenies, 60 repetitions (blocks), totaling 1,500 trees. Each plot was represented by a single tree, spaced $4 \times 4 \mathrm{~m}$ (2.4 ha). After 21 years (2005) of growth, 250 of the best trees within families of the PP were selected for dbh growth traits (the other $83.3 \%$ were logged), resulting in a seedling seed orchard (SSO) with a predicted genetic gain of $5.0 \%$. Each of the original 25 families was represented in the SSO by at least 3 trees (maximum of 29). For molecular analysis, all 250 trees from the SSO were mapped, sampled, and genotyped for 11 specific microsatellite loci (SSR).

\section{Progeny test}

After three of logging (June 2008), of the 250 remaining trees in the SSO, seeds were collected from 136 seed trees which were used to establish the PT. All 25 original families of SSO were represented in the sampled family arrays. After collection, the fruits were dried to release seeds, being careful not to allow contamination between seed tree samples. In 2008, the seeds were germinated at Votorantim Celulose e Papel (VCP) Company, in Três Lagoas, Mato Grosso do Sul State, Brazil. That same year, the PT was established in FEIS/UNESP, using a randomized block design, with four repetitions, 136 families and five plants per plot (spaced $1.8 \times 3 \mathrm{~m}$ ), totaling 2,720 trees (1.5 ha). For molecular analysis, we sampled and genotyped (using the same 11 SSR loci) 500 seedlings (20 per seed tree) collected from 25 seed trees of the PT. These 25 seed trees are from different families. However, 38 seedlings from the PT failed to amplify the 11 SSR loci and were discarded from the subsequent analysis, resulting in a sample of 462 seedlings for genetic analyses. To investigate inbreeding depression, we also measured the total height of seedlings at six months of age.

\section{Microsatellite analysis}

Details about the DNA extraction and development of the 11 microsatellite loci are provided in da Silva et al. (2009). In short, DNA extraction from the SSO and PT trees used fresh leaves and the CTAB protocol (Doyle and Doyle, 1990). The 11 loci used were, ECc2, ECc3, ECc4, ECs11, ECc27, ECc31, ECc44, ECc46, ECc64, ECc89, and ECc91.

\section{Analysis of genetic diversity and fixation index}

The frequency and standard error (SE) of null alleles was estimated for adults and seedlings under a population inbreeding model (PIM) using the INEST 2.0 program (Chybicki and Burczyk, 2009). Genetic diversity in the SSO and PT was assessed using the total number of alleles in the loci $(k)$, average number of alleles per locus $(A)$, observed $\left(H_{o}\right)$ and expected heterozygosity $\left(H_{e}\right)$. These analyses were carried out using the FSTAT program (Goudet, 1995). To identify inbreeding in the samples, we estimated the fixation index based on Nei (1977): $F=1-\left(H_{o} / H_{e}\right)$. Because both the SSO and PT are structured in open-pollinated families and as such each plant within a family received at least one of the maternal alleles, the gene frequencies can be overestimated due to the presence of maternal alleles. Thus, the $F$ values for mean SSO and PT populations were estimated using the $H_{o}$ calculated for each population (SSO and PT) and $H_{e}$ was estimated from gene frequencies of the pollen pool of each population using the program MLTR 3.1 (Ritland, 2002). $H_{e}$ was estimated as $H_{e}=1-\sum p_{i}^{2}$, where $p_{i}$ is the frequency of allele $i$ of a locus (Nei, 1977). The $95 \%$ confidence interval $(95 \% \mathrm{Cl})$ of $F$ was estimated using the standard error (lower: $F_{(l)}=F-1.96\left(S D / \sqrt{\left.n_{l}\right)}\right.$; upper: $F_{(u)}=F+1.96\left(S D / \sqrt{\left.n_{l}\right)}\right.$, where SD is the standard deviation of $F$ values among loci and $n_{l}$ is the number of loci ).

\section{Analysis of the intrapopulation spatial genetic structure in SSO}

Although the SSO was established using single tree plots and $83 \%$ of the initially established trees have been logged, we tested for the presence of intrapopulation spatial genetic structure (SGS) because the orchard included many trees from the same seed tree (families). Thus, there is the possibility that trees from the same seed tree (brothers) were planted in proximity. The SGS was determined using the average coancestry coefficient $\left(\theta_{i j}\right)$ between pairwise trees as presented by Loiselle et al. (1995) and implemented in SPAGEDI 1.3 program (Hardy and Vekemans, 2002). To visualise the SGS, $\theta_{i j}$ values were averaged over a set of ten distance classes of varying distances, but with the same number of pairs of individuals, and then plotted against the distance. To test whether there was significant deviation from a random spatial genetic structure, the $95 \%$ confidence interval $(95 \% \mathrm{Cl})$ was calculated for mean coancestry values of each distance class, using 1,000 Monte Carlo permutations of individuals among distance classes.

\section{Mating system analysis}

We analyzed the mating system at the population level for the SSO trees and PT seedlings and at the family level for the PT. These analyses used the mixed mating model and correlated mating model in MLTR 3.1 program (Ritland, 2002), and were based on the numerical method of maximum likelihood EM (Expectation Maximization) due to the uneven number of individuals within families. The estimated indexes were multilocus outcrossing rate $\left(t_{m}\right)$, single-locus outcrossing rate $\left(t_{s}\right)$, outcrossing rate among relatives $\left(t_{m}-t_{s}\right)$, correlation of selfing $\left(r_{s}\right)$, and multilocus paternity correlation $\left(r_{p}\right)$. The $95 \%$ confidence interval $(95 \% \mathrm{Cl})$ was estimated using the $2.5 \%$ of minimum percentile estimated values $\left(F_{m(l)}, t_{m(l)}, s_{(l)}=1-t_{m(u)}\right.$, $r_{s(l)}$, and $\left.r_{p(l)}\right)$ and $97.5 \%$ of maximum percentile estimated values $\left(F_{m(u)}, t_{m(u)}, s_{(u)}=1-t_{m(l)}, r_{s(u)}\right.$, and $\left.r_{p(u)}\right)$, obtained by 1,000 bootstrap resampling. The resampling unit was the progenies within families. These indexes were used to estimate 
the effective number of pollen donors $\left(N_{e p}=1 / r_{p^{\prime}}\right.$ (Ritland, 1989), and average coancestry coefficient within families at the population level as

$\Theta=0.125\left(1+F_{p}\right)\left[4 s+\left(t_{m}^{2}+s t_{m} r_{s}\right)\left(1+r_{p}\right)\right]$ and at the family level for PT as

$\Theta=0.125\left(1+F_{p}\right)\left[4 s+t_{m}^{2}\left(1+r_{p}\right)\right]$ (Sebbenn, 2006), where $s$ is the selfing rate $\left(s=1-t_{m}\right)$. The effective size within families was estimated from the variance in gene frequencies due to genetic drift, following (Cockerham, 1969):

$$
N_{e}=\frac{0.5}{\Theta\left(\frac{n-1}{n}\right)+\frac{1+F}{2 n}},
$$

where, $n$ is the sample size. The $95 \% \mathrm{Cl}$ lower $\left(N_{e p(l)}, \Theta_{(l)}\right.$, and $\left.N_{e(l)}\right)$ and upper $\left(N_{e p(u)} \Theta_{(u)}\right.$, and $\left.N_{e(u)}\right)$ values of the $N_{e p^{\prime}} \Theta$ and $N_{e}$ indexes was estimated by:

$$
\begin{aligned}
& N_{e p(l)}=\frac{1}{r_{p(u)}}, \\
& N_{e p(u)}=\frac{1}{r_{p(l)}}, \\
& \Theta_{(l)}=0.125\left(1+F_{m(l)}\right)\left[4 s_{(l)}+\left(t_{m(u)}^{2}+t_{m(u)} s_{(l)} r_{s(l)}\right)\left(1+r_{p(l)}\right)\right], \\
& \Theta_{(u)}=0.125\left(1+F_{m(u)}\right)\left[4 s_{(u)}+\left(t_{m(l)}^{2}+t_{m(l)} s_{(u)} r_{s(u)}\right)\left(1+r_{p(u)}\right)\right], \\
& N_{e(l)}=\frac{0.5}{\Theta_{(u)}\left(\frac{n-1}{n}\right)+\frac{1+F_{(u)}}{2 n}},
\end{aligned}
$$

and

$$
N_{e(u)}=\frac{0.5}{\Theta_{(l)}\left(\frac{n-1}{n}\right)+\frac{1+F_{(l)}}{2 n}} .
$$

\section{Analysis of group coancestry and variance effective size of the SSO}

The pairwise coancestry coefficient within families $\left(\theta_{i j}\right)$ of the SSO was also calculated using the method presented in Loiselle et al. (1995) and implemented in SPAGEDI 1.3 program (Hardy and Vekemans, 2002). The mean group coancestry within progeny $(\Theta)$ was calculated as:

$\Theta=\frac{\sum_{i=1}^{n} 0.5\left(1+F_{m}\right)+\sum_{i=1}^{n} \sum_{i \neq j}^{n} \theta_{i j}}{n^{2}}$,

where $n$ is the number of individuals within families, $F_{m}$ is the fixation index of seed trees, estimated using SPAGEDI program, $\sum_{i=1}^{n}$ is the sum of all individuals within the family and $\sum_{i=1}^{n} \sum_{i \neq j}^{n}$ is the sum of pairwise individuals within family. As $\Theta$ was derived from the inbreeding coefficient of seed trees (ranging from 0 to 1 ), but $F_{m}$ was estimated from fixation index (ranging from -1 to 1), negative $F_{m}$ values were assumed to be zero. Furthermore, the expected minimum pairwise $\theta_{i j}$ value within families is 0.125 (half-sibs), but as we estimated $\theta_{i j}$ using the method described by (Loiselle et al., 1995), and based on a correlation coefficient (range from -1 to 1), values lower than 0.125 were assumed to be 0.125 . The group coancestry of the SSO $\left(\Theta_{t}\right)$, assuming an absence of relatedness among individuals of different families $\left(\theta_{i j}=0\right)$, was estimated using the expression:

$$
\Theta_{t}=\frac{\sum_{i=1}^{n_{S S O}} \Theta}{n_{t}^{2}}
$$

where $n_{t}$ is the total number of individuals in the SSO (250), $n_{\text {sso }}$ is the number of seed trees that originally formed the SSO (25), $n$ is the number of individuals within families (ranging among seed trees from 3 to 29), $\sum_{i=1}^{n_{\text {sso }}}$ is the sum of all 25 families. Based on the approach described by Cockerham (1969) to estimate sample variance in gene frequencies from genetic drift, $\sigma_{p_{i}}^{2}=p_{i}\left(1-p_{i}\right) \Theta$ and sample variance in gene frequencies of a population without inbreeding and relatedness $\sigma_{p_{i}}^{2}=p_{i}\left(1-p_{i}\right) / 2 N_{e}$, where $p_{i}$ is the frequency of allele $i$, we estimated the variance effective size within families $\left(N_{e}\right)$ and total family arrays $\left(N_{e(t)}\right)$ as:

$p_{i}\left(1-p_{i}\right) \Theta=\frac{p_{i}\left(1-p_{i}\right)}{2 N_{e}}$

$N_{e}=\frac{p_{i}\left(1-p_{i}\right)}{2 p_{i}\left(1-p_{1}\right) \Theta}$

thus, $N_{e}=0.5 / \Theta$ or

$N_{e(t)}=0.5 / \Theta_{t}$, respectively.

\section{Paternity analysis}

The combined non-exclusion probability of identity $\left(Q_{i}\right)$, the combined non-exclusion probability of the second parent $\left(P_{2}\right)$ for 250 adults of SSO, as well as the paternity analysis was estimated using the Cervus 3.0 program (Kalinowski et al., 2007; Marshall et al., 1998). The cryptic pollen flow $\left(C_{p p}\right)$ was estimated following Doyle and Doyle (1990) as $C_{p f}=1-\left(1-P_{2}\right)^{n_{c}}$, where $n_{c}$ is the number of candidate pollen donors in the SSO (250). Paternity analysis was carried out by maximum-likelihood paternity assignment (Meagher, 1986), based on the multilocus genotypes of the 462 open-pollinated seedlings sampled from the PT and all 250 adult trees of the SSO as pollen candidate parents. The most likely parent pair for each seedling was determined by the $\Delta$ statistic (Marshall et al., 1998), using the reference allele frequencies calculated for the adults of SSO, as suggested by Meagher and Thompson (1987). To assign a seedling to a pollen donor, we accepted a maximum of two mismatches in at least seven loci compared among the seedling-mother-father trio. Significance for $\Delta$ was determined through paternity tests simulated by the software (critical $\Delta$ ) using a confidence level of $80 \%$, a genotyping error ratio of $0.01,50,000$ repetitions, and all 250 reproductive trees of the SSO as putative pollen candidates. As there is no record 
of other nearby stands of the species to the SSO (>50 km) and we observed that flowering of E. camaldulensis was asynchronous with E. grandis, E. urophylla, and E. pelita trials established in the experimental station, calculation of critical $\Delta$ values was based on the assumption that $100 \%$ of candidate pollen parents were located within SSO. If a pollen donor had a $\Delta$ value higher than the critical $\Delta$ value calculated by simulations, it was considered as the true pollen parent. The pollen immigration rate $\left(m_{p}\right)$ was estimated as the proportion of seedlings for which the father was not found inside the SSO $\left(n_{i}\right)$ in relation to the total sample seedlings $(n): m_{p}=n_{i} / n$. If the same individual was found to be the maternal and paternal parent, the seedling was considered as a selfed seedlings and the selfing rate $(s)$ was calculated by dividing the number of selfed seedlings $\left(n_{s}\right)$ by the total number of sampled seedlings $(n): s=n_{s} / n$. The standard error of average selfing rate was estimated assuming binomial distribution as $S E(s)=\sqrt{\left.s(1-s) / n_{s t}\right)}$ (Slavov et al., 2005), where $n_{s t}$ is the number of sampled seed trees that originally formed the SSO (25). As the spatial position ( $x$ and $y$ coordinates) was recorded for all trees in the SSO, the distances among seed trees and assigned pollen donors was used to estimate the minimum, maximum, average $(\delta)$, median and standard deviation (SD) distance of pollen dispersal. In order to determine whether mating success was a function of distance between pollen and seed trees, we compared the frequency distribution of effective pollen dispersal distance with the frequency distribution of the distances among trees in the SSO using the Kolmogorov-Smirnov test (Sokal and Rohlf, 1995).

As the pedigree of the 250 trees in SSO is known (as it was established from 25 Australian seed trees), we could also directly calculate the rate of mating among relatives $\left(t_{r}\right)$ in SSO from the assigned seedlings of PT, using paternity analysis: $t_{r}=n_{r} / n$, where $n_{r}$ is the number of seedlings originated from mating among relatives in SSO trees from the same family. The standard error of average $t_{r}$ was estimated assuming binomial distribution as $S E\left(t_{r}\right)=\sqrt{\left.t_{r}\left(1-t_{r}\right) / n_{r}\right)}$. We also estimated the spatial distance $\left(\delta_{r}\right)$, pairwise and mean coancestry coefficient among the assigned father and seed trees in SSO $\left(\theta_{r}\right)$, and fixation index $\left(F_{r}\right)$. Furthermore, we calculated the fixation index of seed trees $\left(F_{m}\right)$ and selfed seedlings ( $F_{s}$, as assigned by paternity analysis). The $\theta_{r}, F_{r}, F_{m}$ and $F_{s}$ indexes were calculated using the SPAGEDI 1.3 program (Hardy and Vekemans, 2002). The $95 \%$ standard error of these estimates was calculated as $S E=1.96(S D / \sqrt{n})$, where $S D$ is the standard deviation and $n$ is the sample size.

\section{Inbreeding depression}

Inbreeding depression for total height at six months of age was estimated for selfed seedlings $\left(I D_{s}\right)$, seedlings from mating among relatives $\left(I D_{r}\right)$, and all inbred seedlings together $\left(I D_{s t}\right)$ as:

$$
\begin{aligned}
& I D_{s}=1-\left(\frac{x_{s}}{x_{t}}\right), \\
& I D_{r}=1-\left(\frac{x_{r}}{x_{t}}\right), \text { and }
\end{aligned}
$$

$I D_{s r}=1-\left(\frac{x_{s r}}{x_{t}}\right)$,

where $x_{s}, x_{r}, x_{s r}$ and $x_{t}$ are the mean height of seedlings originating from selfing, mating among relatives, all inbred seedlings together, and outcrossing among unrelated individuals, respectively.

\section{Results}

\section{Genetic diversity and inbreeding}

When we compared seed trees of the SSO and their openpollinated seedlings in PT, non amplification of alleles was observed at loci ECs11 (20.0 \%), ECc27 (7 \%), ECc44 (12.1\%), and ECC91 (21.2\%). This indicates the presence of null alleles at these loci because many seedlings did not present the maternal alleles and there are more than two homozygous seedlings for homozygous and heterozygous loci in the seed trees. The frequency of null alleles was significant $(P<0.05)$ higher than zero in adults at loci ECc27 $(0.151 \pm 0.032$, frequency \pm 2 SE), ECc44 (0.202 \pm 0.026$)$, ECc46 $(0.187 \pm 0.036)$, and ECC91 $(0.496 \pm 0.021)$ and in seedlings at loci ECs11 (0.238 \pm $0.040), E C c 27(0.176 \pm 0.040), E C c 44(0.423 \pm 0.366)$, and ECc91 $(0.534 \pm 0.028)$. Thus, the loci ECs11, ECc27, ECc44, and ECc91se four loci were excluded and we based the genetic and statistical analyses on the remaining seven loci.

Table 1

Results of genetic diversity and inbreeding in a seedling seed orchard (SSO) and a progeny test (PT) of Eucalyptus camaldulensis. SD is the standard deviation.

\begin{tabular}{lcc} 
Index & SSO & PT \\
\hline Sample size: $n$ & 250 & 462 \\
Total number of alleles: $k$ & 73 & 72 \\
Allelic richness: $R \pm$ SD & $10.4 \pm 5.9$ & $10.2 \pm 5.6$ \\
Observed heterozygosity: $H_{o} \pm$ SD & $0.73 \pm 0.20$ & $0.72 \pm 0.17$ \\
Expected heterozygosity: $H_{e} \pm \mathrm{SD}$ & $0.73 \pm 0.17$ & $0.74 \pm 0.15$ \\
Fixation index: $F \pm \mathrm{SD}$ & $0.08 \pm 0.16$ & $0.10 \pm 0.05^{*}$ \\
${ }^{*} \mathrm{P}<0.05$ & &
\end{tabular}

The total number of alleles over all loci $(k)$, mean allelic richness $(R)$, mean observed $\left(H_{o}\right)$ and expected heterozygosity $\left(H_{e}\right)$ were similar between the SSO and PT (Table 1). The mean fixation index $(F)$ was significantly higher than zero only for the PT $(F=0.10, \mathrm{P}<0.05)$, suggesting inbreeding.

\section{Spatial genetic structure in the SSO}

A significant decrease in the mean pairwise coancestry coefficient with an increase in the spatial distance among trees was detected in the SSO up to $32 \mathrm{~m}$ (Figure 1), indicating that near neighbour trees are related. 


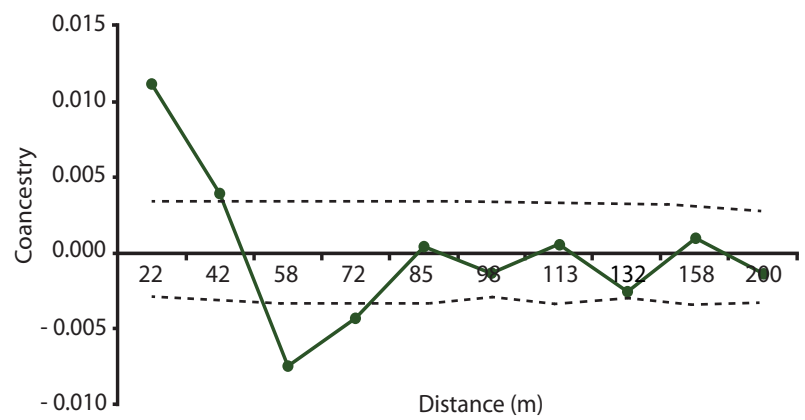

Figure 1

Correlogram of average coancestry coefficients $\left(\Theta_{i j}\right)$ for Eucalyptus camaldulensis trees in the seedling seed orchard (SSO). The solid line represents the average $\Theta_{i j}$ value and the dashed lines represent the $95 \%$ (two-tailed) confidence interval of the average $\Theta_{i j}$ distribution calculated by 1,000 permutations of spatial distance between pairs of trees

\section{Group of coancestry and effective population size of SSO}

The estimated group coancestry of SSO $(\Theta)$ was 0.0107 . Thus, the total effective population size of SSO $\left(N_{e(t)}\right)$ indicates that the 250 trees represent 47 non-inbreed and unrelated trees of a panmictic population $\left(N_{e(t)} / n=47 / 250=0.19\right)$.

\section{Mating system}

The maternal fixation index $\left(F_{m}\right)$ was significantly higher than zero only for the seed trees from $\mathrm{AP}\left(F_{m}=0.055, \mathrm{P}<0.05\right)$, suggesting that some of these trees in the natural population where the seeds to establish the provenance and progeny test were collected are inbred (Table 2). In contrast, the 25 seed trees from the SSO, where the analysed seedlings in PT were sampled have a significantly lower than zero fixation index ( $\left.F_{m}=-0.030, \mathrm{P}<0.05\right)$, suggesting an excess of heterozygous individuals. The outcrossing rate $\left(t_{m}\right)$ was significantly lower than unity (1.0) in the SSO (0.982), ranging among seed trees from 0.811 to 0.989 , suggesting the presence of self-fertilization in SSO and, thus that some selfed individuals in the PT. The difference $t_{m}-t_{s}$ was significantly greater than zero in both AP (0.021) and the SSO (0.050), ranging among seed trees in the SSO from -0.055 to 0.098 , indicating some mating among relatives and that some in the individuals in both trials present inbreeding from mating among relatives. The correlation of selfing $\left(r_{s}\right)$ was significantly greater than zero, but low and similar between AP (0.110) and SSO (0.100), indicating low individual variation in the outcrossing rate. The paternity correlation $\left(r_{p}\right)$ was significantly higher than zero and significant lower in AP (0.018) than in SSO (0.185), ranging among seed trees of SSO from 0.050 to 0.372 , indicating a low frequency of full-sibs within families and a greater number of effective pollen donors $\left(N_{e p}\right)$ in AP produce the trees in the SSO (55.6) than the trees in SSO produced the seedlings of PT (5.4, ranging among seed trees in from 2.7 to 20.0). Consequently, the mean coancestry coefficient within families $(\Theta)$ was lower in SSO (0.134) than PT $(0.152$, ranging among families from 0.134 to 0.185$)$ and the variance effective size $\left(N_{e}\right)$ was significantly higher in SSO (3.28) than in PT (2.93, ranging among families in PT from 2.28 to 3.01 ).

\section{Pollen flow and dispersal patterns in the SSO}

The combined non-exclusion probability of identity was low $\left(Q_{i}=6.95^{-9}\right)$, indicating that the loci used are effective for paternity analysis. The estimated combined non-exclusion probability of the second parent was low $\left(P_{2}=0.001058\right)$, when the first parent is known (in the present case, the mother), resulting in a cryptic pollen flow $\left(C_{p)}\right)$ of 0.232 or the probability that some seeds were assigned for pollen donors within SSO, when the true parent are located outside of the orchard, indicating that pollen flow may be higher than estimated. Due the fact that some adults and seedlings present some missing data, we determined pollen to be from outside the SSO if we found one, two or more than two mismatch when the trio seedling, mother and the putative assigned father by paternity analysis were compared for five, six and seven loci, respectively. Of the

Table 2

Estimates of mating system and genetic indexes at the population level of the seedling seed orchard (SSO) and population and family level of the progeny test (PT). $95 \% \mathrm{Cl}$ is the $95 \%$ confidence interval.

\begin{tabular}{|c|c|c|c|}
\hline Index & $\begin{array}{c}\text { SSO } \\
\text { population }(95 \% \mathrm{Cl})\end{array}$ & $\begin{array}{c}\text { PT } \\
\text { population }(95 \% \mathrm{Cl})\end{array}$ & $\begin{array}{c}\text { PT } \\
\text { family range }\end{array}$ \\
\hline Sample size: $n$ & 250 & 462 & 462 \\
\hline Maternal fixation index: $F_{m}$ & $0.055(0.001 \text { to } 0.102)^{*}$ & $-0.030(-0.060 \text { to }-0.020)^{*}$ & - \\
\hline Multilocus outcrossing rate: $t_{m}$ & $1.000(1.000$ to 1.000$)$ & 0.982 (0.961 to 0.996$)$ & 0.811 to 0.989 \\
\hline Mating among relatives: $t_{m}-t_{s}$ & 0.021 (0.007 to 0.034$)$ & 0.050 (0.035 to 0.059$)$ & -0.055 to 0.098 \\
\hline Correlation of selfing: $r_{s}$ & 0.110 (0.110 to 0.110$)$ & 0.100 (0.069 to 0.110$)$ & - \\
\hline Multilocus paternity correlation: $r_{p}$ & $0.018(0.004$ to 0.028$)$ & 0.185 (0.130 to 0.242$)$ & 0.050 to 0.372 \\
\hline Effective number of pollen donors: $N_{e p}$ & 55.6 (35.7 to 250.0 ) & 5.4 (4.1 to 7.7$)$ & 2.7 to 20.0 \\
\hline Coancestry within the progeny: $\Theta$ & 0.134 (0.126 to 0.142$)$ & 0.152 (0.150 to 0.152 ) & 0.134 to 0.185 \\
\hline Variance effective size: $N_{e}$ & 3.28 (3.13 to 3.46$)$ & 2.93 (2.86 to 2.98$)$ & 2.28 to 3.01 \\
\hline${ }^{*} \mathrm{P}<0.05$ & & & \\
\hline
\end{tabular}


462 seedlings, 65 presented more than two mismatch in at least seven of the compared loci among the seedling-mother-father trio, indicating a pollen flow $\left(m_{p}\right)$ from outside the SSO of 0.141 . Of the 397 remaining seedlings (462-65), 354 were assigned for one putative pollen donor, 37 for two, 5 for three, and 1 seedling for four. To avoid bias in the estimates of pollen dispersal distance and patterns, we used only the 354 seedlings with only one assigned pollen donor. Of these seedlings, 202 were fathered by trees of the same provenance $(57.1 \%)$ and 152 seedlings were fathered by trees of different provenances (42.9\%). Of the 250 pollen parent candidates in the SSO, $156(62.4 \%)$ pollinated at least one seedling, to a maximum of 13 seedlings. We found the same pollen donor as the seed tree for 15 seedlings, indicating a mean selfing rate $(s)$ of 0.032 . The fixation index for seedlings originating from selfing $\left(F_{s}\right)$ ranged from 0.111 to 0.636 , with a mean of 0.275 . Excluding selfing, the distance of pollen dispersal ranged from 3 to $242 \mathrm{~m}$, with a mean $(\delta)$ of $94 \mathrm{~m}$ and a median of $90 \mathrm{~m}$ (Table 3, Figure 2), suggesting a pollen dispersal pattern of isolation by distance. The coefficient of determination $\left(R^{2}\right)$ for exponential regression between frequency of assigned seedlings on different distance classes was high and significant (0.714, $\mathrm{P}>0.01, \mathrm{df}=8)$, further indicating a pollen dispersal pattern of isolation by distance (Figure 2). Additionally, the Kolmogorov-Smirnov test, comparing the frequency curve of pollen dispersal distance with the frequency curve of distance measured among all 250 trees to the 25 seed trees of the SSO,

Table 3

Results of paternity analysis in the seedling seed orchard (SSO). SE is the standard error; SD is the standard deviation.

\begin{tabular}{|c|c|}
\hline & Estimates \\
\hline Number of sampled seedlings: $n$ & 462 \\
\hline Number of seedlings not assigned a pollen donor: $n_{i}$ & 65 \\
\hline Pollen flow: $m_{p}=n_{i} / n$ & 0.141 \\
\hline Number of seedling assigned within SSO: $n_{w}$ & 397 \\
\hline Number of seedlings assigned with one pollen donor: $n_{u}$ & 354 \\
\hline Number of seedlings assigned for the same seed tree: $n_{s}$ & 15 \\
\hline Selfing rate: $s=n_{s} / n( \pm \mathrm{SE})$ & $0.032 \pm 0.035$ \\
\hline Mean fixation index of selfed seedlings: $F_{s} \pm \mathrm{SE}$ & $0.275 \pm 0.079$ \\
\hline Minimum/maximum fixation index of selfed seedlings & $0.111 / 0.636$ \\
\hline Mean pollen dispersal distance: $\delta \pm \mathrm{SD}$ & $94 \pm 58 m$ \\
\hline Minimum/maximum pollen dispersal distance & $3 / 242 \mathrm{~m}$ \\
\hline Median pollen dispersal distance & $90 \mathrm{~m}$ \\
\hline Number of assigned seedlings between related parents: $n_{r}$ & 12 \\
\hline Rate of mating among relatives: $t_{r}=n_{r} / n( \pm \mathrm{SE})$ & $0.026 \pm 0.046$ \\
\hline Mean coancestry between related parents: $\theta_{r} \pm \mathrm{SE}$ & $0.133 \pm 0.054$ \\
\hline Minimum/maximum coancestry between related parents & $-0.022 / 0.309$ \\
\hline Mean distance between related parents: $\delta_{r} \pm \mathrm{SE}$ & $124 \pm 34 m$ \\
\hline Minimum/maximum distance between related parents & $49 / 242 m$ \\
\hline Mean fixation index of seedlings originated from $t_{r}: F_{r} \pm \mathrm{SE}$ & $0.138 \pm 0.199$ \\
\hline $\begin{array}{l}\text { Minimum/maximum fixation index of seedlings originated } \\
\text { from } t_{r}\end{array}$ & $-0.090 / 0.533$ \\
\hline${ }^{*} P<0.05$ & \\
\hline
\end{tabular}

where the analysed seedlings in PT were sampled was significantly different from zero ( $D=0.097, \mathrm{P}=0.004$, Figure 2), suggesting non-random mating. The mean pairwise coancestry coefficient among the related parents $\left(\theta_{r}=0.133\right)$ was close to that expected for half-sibs (0.125) and the distance of pollen dispersal for mating among relatives $\left(\delta_{r}\right)$ ranged from 49 to $242 \mathrm{~m}$, with a mean of $124 \mathrm{~m}$. The fixation index for seedlings originating from mating among relatives $\left(F_{r}\right)$ ranged from -0.090 to 0.533 , with a mean of 0.138 .

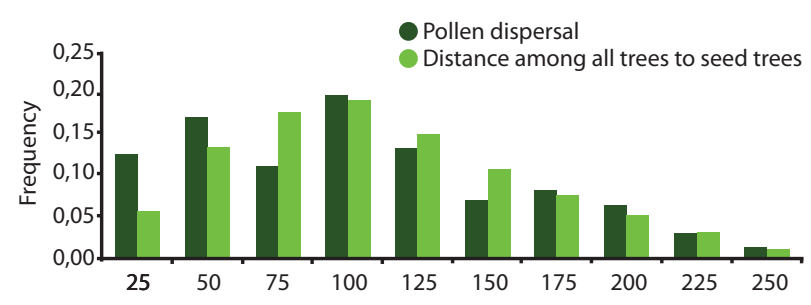

Figure 2

Frequency of pollen dispersal distance among all trees to seed trees in the seedling seed orchard (SSO)

\section{Inbreeding depression}

The mean height for the 15 seedlings that originated from selfing $\left(x_{s}=2.56 \mathrm{~m}\right)$, the 12 from mating among relatives $\left(x_{r}=2.97 \mathrm{~m}\right)$, and all 27 inbred seedlings together $\left(x_{s r}=2.74 \mathrm{~m}\right)$ was lower than the 314 seedlings resulting from outcrossing $\left(x_{t}=3.03 \mathrm{~m}\right)$. The mean inbreeding depression was $15.6 \%$ for selfed seedlings, $2.0 \%$ for seedlings from mating among relatives, and $9.5 \%$ for all inbred seedlings.

\section{Discussion}

\section{Variance effective size of SSO}

The SSO is obviously genetically structured due to the fact that many trees are from the same families. The SSO presents SGS and the mean pairwise coancestry coefficient decreases with an increase in the spatial distance between trees up to about $32 \mathrm{~m}$ (Figure 1), indicating that some near neighbour trees are related. To establish the SSO, we selected between 3 and 29 of the best trees for growth in dbh from the 25 original families. Even when using single tree plots, it is inevitable that some near neighbour trees among blocks are siblings, due to the randomization of families within blocks. Thus, the estimated group coancestry resulted in a total effective population size $\left(N_{e(t)}=47\right)$ lower than the number of selected trees for the SSO ( $n=250 ; N_{e(t)} / n=0.19$ ). The existence of SGS can result in mating among relatives and inbred seeds, as was detected here using both the mixed mating model and paternity analysis. If individuals within families are half-sibs, the maximum inbreeding from mating among relatives will be 0.125 . The $N_{e(t)}$ can increase only if non-inbred half-sibs within families are selected to create the SSO. For example, if the 250 selected individuals in the SSO are not inbred, unrelated from different families, and half-sibs within families, the $N_{e(t)}$ would be 77 and $N_{e(t)} / n=0.31$. Thus, our SSO had a $N_{e(t)} 39 \%[100(1-(47 / 77))]$ 
lower than that expected for a seedling seed orchard with the lowest possible within family relatedness and without inbreeding.

\section{Mating system}

Our mating system results based on the 250 trees of SSO represent the mating pattern of seed trees from the two Australian provenances (AP), where seeds were collected to establish the PP. In contrast, the results on the seedlings of PT represent the mating pattern in the SSO. Furthermore, the results for both SSO and PT represent the realized mating system, not what effectively occurred during reproductive events. We used established seedlings for our analyses and, as such, many processes may have affected the SSO and PT trees between fertilization and our assessment of the genotypes, such as natural and artificial selection against inbred seeds, random mortality, and disease.

The AP seed trees, where seeds were collected to establish the PP and subsequently the SSO, presented some inbreeding $\left(F_{m}=0.055\right)$. In contrast, the 25 seed trees of the SSO which produced the sampled and genotyped seedlings of the PT are not inbred $\left(F_{m}=-0.030\right)$. Furthermore, the fixation index $(F)$ estimated for the 250 trees of the SSO indicates that the trees selected to make up the SSO did not include inbred individuals (Table 1). The mixed mating model indicates that the 250 trees of the SSO were all produced by outcrossing $\left(t_{m}=1.0\right)$, with a small proportion originating from mating among relatives $\left(t_{m}-t_{s}=0.021\right)$ and correlated mating $\left(r_{p}=0.018\right)$. Thus, the majority of trees within families are half-sibs $(\Theta=0.134)$. Similarly, the sampled seedlings from PT were also in general produced by outcrossing in SSO $\left(t_{m}=0.981\right)$, with a low proportion from mating among relatives $\left(t_{m}-t_{s}=0.050\right)$ and correlated matings $\left(r_{p}=0.185\right)$, suggesting again that the majority of seedlings within families are half-sibs $(\Theta=0.152)$. However, the effective number of pollen donors was significantly higher in SSO $\left(N_{e p}=55.6\right)$ than PT ( $\left.N_{e p}=5.4\right)$, which explains the higher $\Theta$ and lower variance effective size within families for PT $\left(N_{e}=2.93\right)$. The selfing and mating among relatives in SSO can explain inbreeding in PT $(F=0.10)$. Inbreeding increases the frequency of identical by descent alleles (IBD) within individuals and relatedness increases the IBD among individuals, thus decreasing the $N_{e}$. Therefore, as the families of PT are not half-sib families, the additive genetic variance $\left(\sigma_{A}^{2}=\sigma_{f}^{2} / \rho\right.$, where $\sigma_{f}^{2}$ is the genetic variance among families and $\rho$ is the average coefficient of relatedness within families, calculated in the case of non-inbred parental populations as $\rho=2 \Theta$ ) must be adjusted to estimate heritability and genetic gains. In halfsib families, $\rho$ is 0.25 and the additive genetic variance is estimated as $\sigma_{A}^{2}=\sigma_{f}^{2} / 0.25$. However, for the present case of the $E$. camaldulensis PT, the $\sigma_{A}^{2}$ must be estimated using $\sigma_{f}^{2} / 2 x 0.152=\sigma_{f}^{2} / 0.304$ to avoid overestimations in calculating heritability and genetic gains.

\section{Pollen flow and dispersal patterns in the SSO}

Pollen immigration in the SSO was lower ( $\left.m_{p}=14.1 \%\right)$ than detected in other Eucalyptus spp seed orchards: $56.7 \%$ in E. regnans (Burczyk et al., 2002), 29 \% in E. grandis x E. urophylla
(Grattapaglia et al., 2004), and $46.5 \%$ in E. grandis (Chaix et al., 2010). As the SSO was spatially isolated from conspecific individuals, this pollen flow may represent hybridization with other species established in the area, such as $E$. grandis, E. urophylla, and E. pellita. An alternative explanation is genotyping errors, resulting in some unassigned seedlings within the SSO. The least probable explanation is hybridization as we observed that the flowering of E. grandis, E. urophylla, and E. pelita in the area was asynchronous with E. camaldulensis flowering.

Using paternity analysis, our results also indicate that mating is not random in the SSO. We detected selfing, mating among relatives, correlated mating, variation in male fertility ( 1 to 13 seeds), and a pattern of pollen dispersal of isolation by distance, with a high frequency of mating occurring between near neighbor individuals in the SSO, which are strong indicators of genetic drift. Other studies in seed orchards have also found deviation from a random mating pattern (Burczyk et al., 2002; Grattapaglia et al., 2004; Kaya et al., 2006; Moriguchi et al., 2004; Plomion et al., 2001; Slavov et al., 2005; Stoehr and Newton, 2002). In contrast, random mating was detected in an E. grandis seed orchard (Chaix et al., 2010). Genetic gains in seed orchards are predicted based on the hypothesis of random mating and deviation from this expectation results in lower than expected realized genetic gains. Thus, the predicted genetic gains in seeds collected from the SSO (5.0\%) are probably greater than that realized in PT. In order to confirm if the genetic gains are different from the predicted, we must wait until the PT reaches 25 years of age because the estimates are based on a population with the same age and cultivation in a site similar to the SSO.

\section{Genetic diversity in SSO and PT}

The levels of genetic diversity were similar for SSO and PT (Table 1). This result was expected because the selection for $\mathrm{dbh}$ in PP was carried out only within families and individuals from all 25 initially established families remain in the SSO (3 to 29 best trees per family). As the PT was established with seeds collected from more than one sibling from each of the 25 families in the SSO, and $62.4 \%$ of trees in the SSO pollinated at least one seedling of PT, the genes of SSO were present in PT. However, the relatedness among seedlings from the same family and related families, or originating from trees of the same SSO family must be taken into account during the selection of grow traits in PT to avoid increases in the relatedness of selected F2 plus trees, because mating among relatives can result in inbreeding and, consequently, inbreeding depression.

\section{Inbreeding}

The sampled seedlings of PT present some inbreeding (10\%). This inbreeding can be explained by selfing (3.2\%) and mating among relatives (2.6\%) in SSO. As we know the pedigree of the trees in the SSO and the inbreeding from mating among relatives is equal to the coancestry between parents, we estimated the pairwise coancestry coefficient between trees from the same family. The minimum expected coancestry coefficient 
between two trees from the same family is 0.125 (half-sibs). But the estimated values were in some cases lower than 0.125 , ranging from -0.022 to 0.309 . The cause of lower than expected pairwise estimates is the fact that estimates of relatedness based on genetic markers need a large number of loci, ideally about 20 (Moraes et al., 2012; Ritland, 1996; Wang, 2011). The seven loci used here are probably not sufficient for robust estimates of all pairwise coancestry coefficients. For example, mating between two heterozygous individuals for different alleles in a locus, one with the genotype $A_{1} A_{2}$ and the other with genotype $A_{3} A_{4}$ may produce four different full-sib genotypes $\left(A_{1} A_{3}, A_{1} A_{4}, A_{2} A_{3}\right.$, and $\left.A_{2} A_{4}\right)$. Using the method described by (Loiselle et al., 1995), the estimates of coancestry coefficient between full-sibs with pairwise genotypes $A_{1} A_{3}-A_{2} A_{4}$ and $A_{1} A_{4}-A_{2} A_{3}$ will be -0.190 , or lower than expected (0.25). However, when estimates are based on many more loci (approximately 20) the values tend to converge toward the expected value. The limited number of loci used in our study also explains why the estimates of inbreeding from selfing $\left(F_{s}\right)$ in PT using paternity analysis was lower (0.275) than expected $(0.5$, $F_{s}=0.5\left(1+F_{m}\right)$. In contrast, mating among relatives produces inbreeding values $\left(F_{r}=0.138\right)$ similar to the coancestry between the related parents (0.133), supporting our result that the assigned seedlings for $t_{r}$ are correct.

\section{Inbreeding depression}

The mean inbreeding depression for seedling height in PT was higher for selfed seedlings (15.6\%) than for seedlings originating from mating among relatives (2.0\%), with a total of $9.5 \%$ for all inbred seedlings. In seedlings, selfing is expected to produce at least $50 \%$ homozygosity for identical by decent (IBD) alleles from a mother with heterozygous loci. In contrast, mating among relatives is expected to produce homozygosity for IBD alleles equal to the coancestry coefficient between the parents. For example, mating between two full-sibs will produce an inbreeding rate of $25 \%$. Thus, in general, selfing increases the homozygosity of IBD alleles more than mating among relatives, resulting in higher inbreeding depression than mating among relatives, as observed here for E. camaldulensis and by (Chaix et al., 2010) for E. grandis. Our estimated mean pairwise coancestry coefficient between related parents $\left(\theta_{r}=0.138\right)$ suggests that they are generally half-sibs $\left(\theta_{r}=0.125\right)$, which explains the lower level of inbreeding from mating among relatives than from selfing.

Inbreeding depression in Eucalyptus species is well documented. The inbreeding depression for tree height at six months in E. camaldulensis (9.5\%) was similar to that found for E. regnans at 3.7 years of age ( $11 \%$, (Griffin and Cotterill, 1988), but lower than that found for E. nitens at 9 years of age (14\%, (Hardner and Tibbits, 1998), and for E. grandis at 10 months of age (30\%, (Chaix et al., 2010).

\section{Mixed mating model $x$ paternity analysis}

The mating system of E. camaldulensis was investigated using the mixed and correlated mating model and using paternity analysis. The estimated selfing rate $(s)$ in SSO for the mixed mating model was lower (0.018) than from paternity analysis (0.032), but both estimates indicate that the majority of seedlings sampled in PT were the result of outcrossing. However, we cannot discard the possibility that genotyping errors have increased the outcrossing rate because selfed individuals may looks like outcrosses. The rate of mating among relatives for the mixed mating model was higher $\left(t_{m}-t_{s}=0.050\right)$ than from paternity analysis $\left(t_{r}=0.026\right)$. These differences can be explained by the fact that the estimates using the mixed mating model were based on all sampled seedlings in PT $(n=462)$ and paternity analysis was based only on the seedlings assigned for a single putative pollen donor $(n=354)$. Furthermore, the mixed mating system is a model while the paternity analysis is a direct method to assess mating patterns, providing results that do not require any assumptions about mating patterns.

\section{Implications of the results for tree breeding}

The SSO did not present inbreeding, but it did present SGS due to the fact that the individuals selected from the PP to establish the SSO were from the same families and some siblings exist within the SSO. The variance effective population size of the SSO $\left(N_{e(t)}=47\right)$ is similar to what has been suggested for short term genetic conservation ( $N_{e}=50$ ) or 10 generations (Frankel and Soule, 1981), indicating that the SSO has the potential to produce seeds for commercial reforestation. However, due to pollen contamination, selfing, mating among relatives, and correlated mating in the SSO, the mating pattern was nonrandom and the sampled seedlings in PT include inbred individuals and varying levels of relatedness within families such as self-sibs, full-sibs, half-sibs, and self-half-sibs. Even though mating in the SSO is not random, the genetic diversity of SSO was transferred to PT. However, the predicted genetic gains for growth traits in SSO are probably greater than the actual genetic gains in PT. Due to nonrandom mating in the SSO, resulting in a higher within family coancestry coefficient than expected in half-sib families (0.125) in PT, the estimates of additive genetic variance in PT must be corrected to better calculate heritability and genetic gains. Overall, these results indicate that some management strategies can be applied to decrease inbreeding in seeds collected from the SSO. Inbreeding from mating among relatives in the SSO could be avoided by selecting only one tree of the same family. This strategy will decrease the effective population size of SSO to 25. Alternatively, we could cut trees of the same family located within $124 \mathrm{~m}$ of each other, the mean distance at which mating among relatives was detected using paternity analysis. However, the most important strategy is to select well-growing seedlings, without the presence of fungi and diseases at the nursery stage. This will likely eliminate inbred seedlings and, consequently, decrease the need for subsequent replanting in commercial stands. Finally, our study shows the efficacy of genetic markers for understanding mating processes and the importance of this information for seed orchard management, aiming to produce seeds of good genetic quality for commercial stands. 


\section{Acknowledgement}

This work was financed by a grant to Mario L. T. Moraes and Janete M. S. Gonzaga: Fundação de Amparo à Pesquisa do Estado de São Paulo (FAPESP 05/58721-9 and 05/59217-2, respectively). We thank Alonso A. Silva, César Seleguin, José Cambuim, Juliano B. Abreu, and Manoel Bonfim for assistance with sample collection; Cecília L. Dourado, Flávio C. Arantes, Izabel Afonso, Juliana P. Moreira, Laila T. Cardin, and Patrícia F. Alves for help with seedling DNA extraction and installation of the progeny test. Alexandre M. Sebbenn, Miguel L. M. Freitas and Mario L. T. Moraes are supported by CNPq research fellowships. Finally, we thank Dr. Evelyn Nimmo for her editing of the English of the manuscript.

\section{References}

Ashley MV (2010) Plant Parentage, Pollination, and Dispersal: How DNA Microsatellites Have Altered the Landscape. Critical Reviews in Plant Sciences 29(3):148-161

Askew GR, Elkassaby YA (1994) Estimation of relationship coefficients among progeny derived from wind pollinated orchard seeds. Theoretical and Applied Genetics 88(2):267-272

Burczyk J, Adams WT, Moran GF, Griffin AR (2002) Complex patterns of mating revealed in a Eucalyptus regnans seed orchard using allozyme markers and the neighbourhood model. Molecular Ecology 11(11):2379-2391

Burczyk J, DiFazio S, Adams W (2004) Gene flow in forest trees: how far do genes really travel? Forest Genetics 11(3/4):1-14

Butcher P, Williams E (2002) Variation in outcrossing rates and growth in Eucalyptus camaldulensis from the Petford Region, Queensland; evidence of outbreeding depression. Silvae Genetica 51(1):6-12

Butcher PA, Otero A, McDonald MW, Moran GF (2002) Nuclear RFLP variation in Eucalyptus camaldulensis Dehnh. from northern Australia. Heredity 88:402412

Chaix G, Vigneron P, Razafimaharo V, Hamon S (2010) Improved management of Malagasy Eucalyptus grandis seed orchards using microsatellites and paternity assignment. Journal of Tropical Forest Science:271-280

Chybicki IJ, Burczyk J (2009) Simultaneous Estimation of Null Alleles and Inbreeding Coefficients. Journal of Heredity 100(1):106-113

Cockerham CC (1969) Variance of Gene Frequencies. Evolution 23(1):72-84 da Silva JM, de Sousa ACB, De Souza AP, Mori ES, Freitas MLM, Sebbenn AM, de Moraes MLT (2009) Development and characterization of 14 microsatellite loci from an enriched genomic library of Eucalyptus camaldulensis Dehnh. Conservation Genetics Resources 1(1):465-469

Doyle J, Doyle J (1990) Isolation of DNA from small amounts of plant tissues. BRL focus 12:13-15

El-Kassaby Y, Funda T, Liewlaksaneeyanawin C (2015) Increasing Breeding without Breeding (BwB) Efficiency: Full-vs. Partial-Pedigree Reconstruction in Lodgepole Pine. SOJ Genet Sci 2(1):1-6

El-Kassaby YA, Funda T, Lai BS (2010) Female reproductive success variation in a Pseudotsuga menziesii seed orchard as revealed by pedigree reconstruction from a bulk seed collection. Journal of heredity 101(2):164-168

EMBRAPA (1999) Sistema brasileiro de classificação de solos. EMBRAPA/CNPSO, Rio de Janeiro 412

Frankel OH, Soule ME (1981) Conservation and evolution. New York, N.Y., USA Cambridge, England. Illus: Cambridge University Press, 327 p

Funda T, Liewlaksaneeyanawin C, El-Kassaby YA (2014) Determination of paternal and maternal parentage in lodgepole pine seed: full versus partial pedigree reconstruction. Canadian Journal of Forest Research 44(9):1122-1127

Goudet J (1995) FSTAT (Version 2.9.3.2.): a computer program to calculate F-statistics. Journal of Heredity 86(6):485-486

Grattapaglia D, do Amaral Diener PS, Dos Santos GA (2014) Performance of microsatellites for parentage assignment following mass controlled pollination in a clonal seed orchard of loblolly pine (Pinus taeda L.). Tree Genetics \& Genomes 10(6):1631-1643
Grattapaglia D, Ribeiro V, Rezende GDS (2004) Retrospective selection of elite parent trees using paternity testing with microsatellite markers: an alternative short term breeding tactic for Eucalyptus. Theoretical and Applied Genetics 109(1):192-199

Griffin A, Cotterill P (1988) Genetic variation in growth of outcrossed, selfed and open-pollinated progenies of Eucalyptus regnans and some implications for breeding strategy. Silvae Genetica 37(3-4):124-131

Hardner C, Potts B (1995) Inbreeding depression and changes in variation after selfing in Eucalyptus globulus ssp. globulus. Silvae Genetica 44(1):46-54

Hardner C, Tibbits W (1998) Inbreeding depression for growth, wood and fecundity traits in Eucalyptus nitens. For Genet 5:11-20

Hardy OJ, Vekemans X (2002) SPAGeDi: a versatile computer program to analyse spatial genetic structure at the individual or population levels. Molecular ecology notes 2(4):618-620

Hedrick PW, Hellsten U, Grattapaglia D (2016) Examining the cause of high inbreeding depression: analysis of whole-genome sequence data in 28 selfed progeny of Eucalyptus grandis. New Phytologist 209(2):600-611

Kalinowski ST, Taper ML, Marshall TC (2007) Revising how the computer program CERVUS accommodates genotyping error increases success in paternity assignment. Molecular ecology 16(5):1099-1106

Kaya N, Isik K, Adams W (2006) Mating system and pollen contamination in a Pinus brutia seed orchard. New Forests 31(3):409-416

Loiselle BA, Sork VL, Nason J, Graham C (1995) Spatial genetic structure of a tropical understory shrub, Psychotria officinalis (Rubiaceae). American Journal of Botany 82(11):1420-1425

Marshall T, Slate J, Kruuk L, Pemberton J (1998) Statistical confidence for likelihood-based paternity inference in natural populations. Molecular ecology 7(5):639-655

Meagher TR (1986) Analysis of paternity within a natural population of Chamaelirium luteum. 1. Identification of most-likely male parents. American Naturalist 128(2):199-215

Meagher TR, Thompson E (1987) Analysis of parentage for naturally established seedlings of Chamaelirium luteum (Liliaceae). Ecology 68(4):803-812

Miranda AC, de Moraes MLT, Tambarussi EV, Furtado EL, Mori ES, da Silva PHM, Sebbenn AM (2013) Heritability for resistance to Puccinia psidii Winter rust in Eucalyptus grandis Hill ex Maiden in Southwestern Brazil. Tree Genetics and Genomes 9(2):321-329

Moraes M, Gaino A, Moraes M, Freitas M, Sebbenn A (2012) Estimating coancestry within open-pollinated progenies of dioecious species: the case study of Myracrodruon urundeuva. Silvae Genetica 61(6):256-264

Moriguchi Y, Taira H, Tani N, Tsumura Y (2004) Variation of paternal contribution in a seed orchard of Cryptomeria japonica determined using microsatellite markers. Canadian journal of forest research 34(8):1683-1690

Nanson A (1972) The provenance seedling seed orchard. Silvae Genetica 21(6):243-249

Nei M (1977) F-statistics and analysis of gene diversity in subdivided populations. Annals of Human Genetics 41(2):225-233

Nieto V, Rodriguez J (2003) Eucalyptus camaldulensis Dehnh. Tropical tree seed manual. Washington, DC: United States Department of Agriculture/Forest Service:466-467

Plomion C, LeProvost G, Pot D, Vendramin G, Gerber S, Decroocq S, Brach J, Raffin A, Pastuszka P (2001) Pollen contamination in a maritime pine polycross seed orchard and certification of improved seeds using chloroplast microsatellites. Canadian Journal of Forest Research 31(10):1816-1825

Potts B, Potts W, Cauvin B (1987) Inbreeding and interspecific hybridization in Eucalyptus gunnii. Silvae Genetica 36(5-6):194-199

Pryor L (1976) Biology of Eucalyptus. London: Edward Arnold. Studies in Biology $61: 82 p$

Ritland K (1989) Correlated matings in the partial selfer Mimulus guttatus. Evolution 43(4):848-859

Ritland K (1996) Estimators for pairwise relatedness and individual inbreeding coefficients. Genetical Research 67(02):175-185

Ritland K (2002) Extensions of models for the estimation of mating system using $\mathrm{n}$ independent loci. Heredity 88(4):221-228

Sebbenn A (2006) Sistema de reprodução em espécies arbóreas tropicais e suas implicações para a seleção de árvores matrizes para reflorestamentos ambientais. HIGA AR; SILVA, LD Pomar de sementes de espécies florestais nativas. Curitiba: FUPEF:93-138 
Silva JCE, Hardner C, Tilyard P, Potts BM (2011) The effects of age and environment on the expression of inbreeding depression in Eucalyptus globulus. Heredity 107(1):50-60

Slavov GT, Howe GT, Adams WT (2005) Pollen contamination and mating patterns in a Douglas-fir seed orchard as measured by simple sequence repeat markers. Canadian Journal of Forest Research 35(7):1592-1603

Sokal R, Rohlf F (1995) Biometry: principles and practices of statistics in biological research. WH Freeman and Company, New York,

Stoehr MU, Newton CH (2002) Evaluation of mating dynamics in a lodgepole pine seed orchard using chloroplast DNA markers. Canadian Journal of Forest Research 32(3):469-476

Wang J (2011) Unbiased relatedness estimation in structured populations. Genetics 187(3):887-901

Wang K (2004) Gene flow in European beech (Fagus sylvatica L.). Genetica 122(2):105-113

Wu S, Xu J, Lu Z, Li G, Pan L, Han C (2015) Effects of inbreeding on growth and wood properties of selfed Eucalyptus urophylla progenies. Journal of Tropical Forest Science 27:369-375 